\title{
Mathematical Modeling of Food Freezing in Air-Blast Freezer
}

\author{
Guiqiang Wang and Pinghua Zou
}

\begin{abstract}
A mathematical model for simulating the heat transfer during food freezing was presented. The model consists of three steps. First, the flow field inside the freezing chamber was modeled using the CFD method, based on which the freezing condition, including the temperature and velocity around the food, was calculated. Second, the heat transfer coefficient between food and air was calculated in the CFD model. Third, a finite-difference model was employed to simulate the heat transfer inside the food product. Measurements were conducted on different food products in freezing chamber to verify the mathematical model. The effects of process parameters on food freezing were also analyzed, which concludes that the air temperature has more influence on food freezing than the air velocity.
\end{abstract}

Index Terms-Air-blast freezer, food freezing, package.

\section{INTRODUCTION}

Cooling and freezing are effective ways to preserve food products, among which air-blast is the most commonly used method. In air-blast freezer the temperature of product is reduced by the heat conduction inside the product while convective heat transfer takes place at the product surface. Meanwhile water from inside diffuses towards the surface to make up for evaporation which results from the convective moisture transfer to air if the product is unwrapped [1]. The intensity of the phenomenon depends on air temperature, relative humidity and flow field around the food product [2].

Both heat and moisture transfer are affected by airflow characteristics, product shape and arrangement, which actually determine the heat and mass transfer coefficients. For products with curved surface, flow separation occurs leading to wake formation, in which case transfer coefficients cannot be calculated by analytical solutions, and numerical method need to be used [3]. CFD appears as an powerful tool for simulating the flow field and calculating the transfer coefficients around food product [4]-[6].

The aim of the current work was to model the heat transfer of food freezing and analyze the effects of freezing condition on food freezing. The model was then validated using freezing experiments on food products with different packages.

Manuscript received February 17, 2014; revised April 5, 2014. This work was supported in part by the Heilongjiang Municipal Natural Science Foundation.

Guiqiang Wang and Pinghua Zou are with the Harbin Institute of Technology, Harbin, 150090 China (e-mail: wgq_hit@126.com).

\section{Mathematical Model}

\section{A. CFD Modeling of Flow Field in Freezing Chamber}

The food products are always frozen to $-15^{\circ} \mathrm{C}$ in an air-blast freezer in typical freezing process, in which air is cooled down and forced to circle by air cooler. The geometry of freezer studied in this paper was show in Fig. 1. Food products were placed at the center of the freezer.

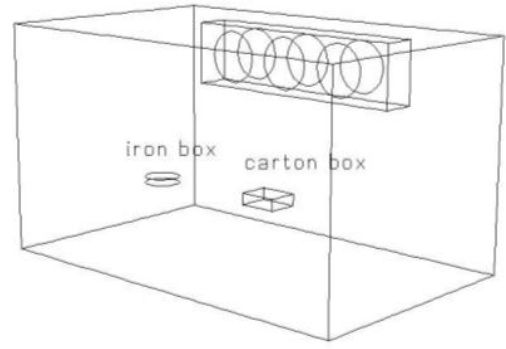

Fig. 1. Geometry of air-blast freezer.

A steady state simulation was conducted on the air phase to model airflow patterns and the heat transfer with products inside the freezing chamber. The model was valid under the assumption that the heat transfer coefficient was constant during the freezing period. If the natural convection was taken into account in the above model, the heat transfer coefficient would change with the airflow patterns. However, the effects of natural convection could be ignored for the air velocity higher than $0.5 \mathrm{~m} / \mathrm{s}$, which is the fact in air-blast freezer [1]. The natural convection also tends to make the model slow to converge and sometimes unstable [6].

The Fluent enhanced wall treatment was used on the product side in order to calculate the heat transfer coefficient accurately. A non-uniform structured mesh was constructed with a higher resolution near the surface of product, where the mesh need to be fine enough to solve the heat transport equations down to the laminar sub-layer $\left(y^{+}=1\right)$.

\section{B. Heat Transfer Coefficient Calculation}

To model the heat transfer between food and air, the temperature of food surface was assumed to be constant, which has been proved to be an effective way. The temperature profile in the air control volume next to the surface was used to calculate the surface heat flux $q_{\text {conv }}[1]$ :

$$
q_{\text {conv }}=k_{\mathrm{a}}\left(T_{\mathrm{s}}-T_{\mathrm{c}}\right) / d_{\mathrm{s}}
$$

where $k_{\mathrm{a}}$ is the thermal conductivity of air, $T_{\mathrm{s}}$ is the surface temperature of food, and $T_{\mathrm{c}}$ is the temperature of air control volume next to the food surface.

Then the convective heat flux $q_{\text {conv }}$ was used to calculate the local surface heat transfer coefficients ht as follows: 


$$
h_{\mathrm{t}}=q_{\mathrm{conv}} /\left(T_{\mathrm{s}}-T_{\mathrm{a}}\right)
$$

where $T_{\mathrm{a}}$ is the air temperature of main stream.

The local surface heat transfer coefficients along the air blast direction were shown in Fig. 2.

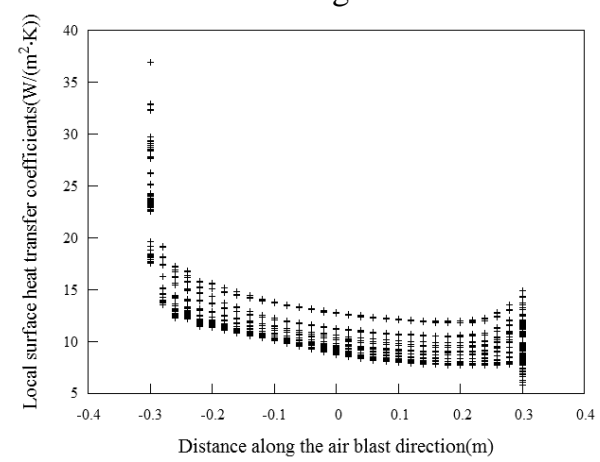

Fig. 2. Local surface heat transfer coefficients along the blow direction.

To analyze the effects of freezing condition on food freezing, the average surface heat transfer coefficient was taken into account. The average surface heat transfer coefficient can be calculated by the integration of local surface heat transfer coefficients [7], and then applied in the food freezing model, as well as the air temperature calculated around the food. A series of simulations were carried out at different air velocities, the results of which were fitted into a regression equation in terms of dimensionless numbers [6]:

$$
N u=C R e^{\mathrm{m}} \operatorname{Pr}^{1 / 3} T u^{\mathrm{A}}
$$

where $N u$ is the Reynolds number, $P r$ is the Prandtl number, $T u$ is the turbulence intensity of air around food. $C, \mathrm{~m}, \mathrm{~A}$ are empirical parameters.

\section{Modeling of Food Freezing}

Inside the food product, heat transfer happens throughout the inner region of food, while only the surface region loses water. The food products employed in the study were pork cuts covered with plastic film inside cardboard box and iron box. Because of the presence of film, the moisture transfer can be ignored in the simulation. The Fourier heat conduction equation applies in food product during freezing period [8]:

$$
\rho_{\mathrm{m}} c_{\mathrm{m}} \frac{\partial T_{\mathrm{m}}}{\partial t}=\nabla\left(k_{\mathrm{m}} \nabla T_{\mathrm{m}}\right)+q_{\mathrm{m}}
$$

where $\rho_{\mathrm{m}}$ is the density, $\mathrm{cm}$ is the specific capacity, and $k_{\mathrm{m}}$ is the thermal conductivity of food. $q_{\mathrm{m}}$ is the heat source term, including the heat fluxes from boundaries.

To simplify the analysis, the food product was treated as infinite slab, and an explicit finite difference scheme was used to solve the model. Quasi-enthalpy method was used to deal with the latent heat release, and the Kirchhoff transformation was used to deal with the variable thermal conductivity. Full details of calculation technique are given by Dawen Sun [8].

The geometry of food product can be seen in Fig. 3. At the presence of air layer between packaging and food, the effective heat resistance of top surface of food is larger than its bottom surface, which was calculated based the type and thickness of packaging. A series of simulations were conducted at different air velocities (from $0.5 \mathrm{~m} / \mathrm{s}$ to $4.5 \mathrm{~m} / \mathrm{s}$ ) and different air temperatures(from $-60^{\circ} \mathrm{C}$ to $-20^{\circ} \mathrm{C}$ ) to analyze the influence of air parameters on freezing time and freezing speed. The freezing speed is the ratio between the minimum distance from the surface to the thermal center and the time elapsed between the surface reaching $0^{\circ} \mathrm{C}$ and the thermal center reaching $5^{\circ} \mathrm{C}$ colder than the temperature of initial ice formation at the thermal center, which was defined by the International Institute of Refrigeration(IIR) [9].

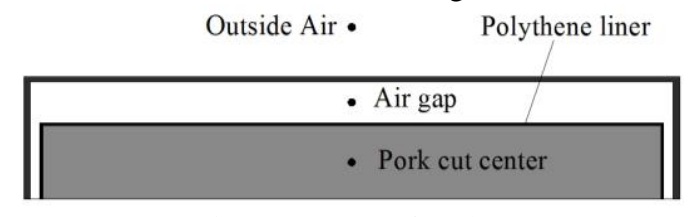

Fig. 3. Geometry of products.

\section{EXPERIMENTAL VERIFICATION}

In order to verify the simulation, experiments were carried out in an air-blast freezer. During the freezing process, the air-cooler fans were running all the time, and the air temperature in the freezing chamber was kept between upper and lower limits. The air temperatures for the on/off control algorithm were $-26^{\circ} \mathrm{C}$ compressor-on temperature and $-16^{\circ} \mathrm{C}$ compressor-off temperature. Thermocouples were placed in the freezer to record the air temperature and relative humidity every 5 minutes, which was shown in Fig. 4.

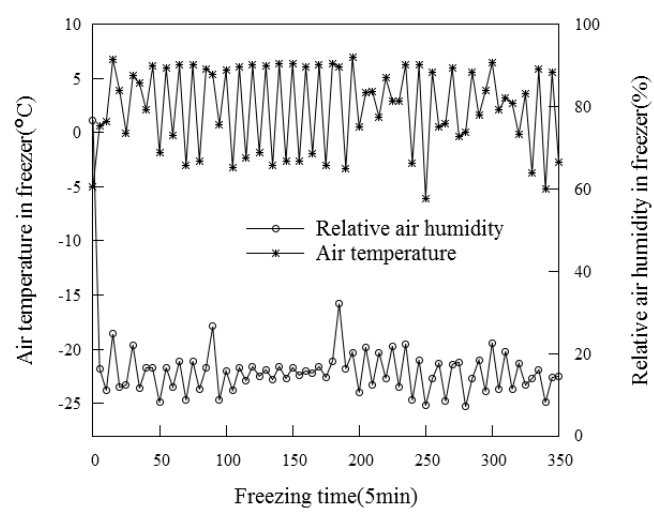

Fig. 4. Air temperature and relative humidity in freezer.

The outlet velocity of fan was measured and averaged to be $7.88 \mathrm{~m} / \mathrm{s}$ using a hot-wire anemometer [10], which was shown in Fig. 5 and Table I.

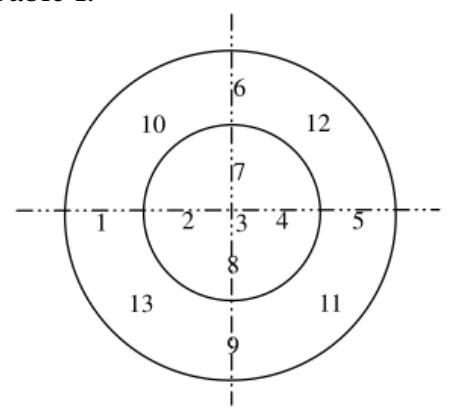

\begin{tabular}{|c|c|c|c|c|c|c|c|}
\hline Measure points & 1 & 2 & 3 & 4 & 5 & 6 & 7 \\
\hline Velocity $(\mathrm{m} / \mathrm{s})$ & 12.9 & 5.3 & 3.3 & 5.6 & 9.3 & 9.7 & 4.2 \\
\hline Measure points & 8 & 9 & 10 & 11 & 12 & 13 & \\
\hline Velocity $(\mathrm{m} / \mathrm{s})$ & 4.4 & 9.7 & 6.9 & 12.0 & 11.1 & 8.1 & \\
\hline $\begin{array}{l}\text { Average } \\
\text { velocity }(\mathrm{m} / \mathrm{s})\end{array}$ & & & & 7.88 & & & \\
\hline
\end{tabular}

Fig. 5. The measurement points arrangement of cold fan.

TABLE I: THE OUTLET VELOCITY OF COLD FAN By MEASUREMENT 
The hot-wire anemometer was then placed at different locations in freezing chamber to measure the air velocity magnitude, and was compared with the flow field predicted by the CFD methods.

Freezing experiments were performed on pork cuts packed in a rectangular carton and a cylindrical iron box to examine the kinetics of food freezing. The pork cuts were wrapped in a thin polyethylene, which has little impact on heat transfer, but prevents the moisture transfer. Thermocouples were placed inside the products to measure the temperature in different depths, including the temperature of air gap, as shown in Fig. 3. The freezing process involves cooling down the food products from $10^{\circ} \mathrm{C}$ to $-15^{\circ} \mathrm{C}$. During freezing process, thermocouples were placed at different locations inside the food products, which was shown in Fig. 3. Temperatures was recorded every 10 minutes.

\section{RESUlTS AND DisCUSSION}

Fig. 6 shows the modeling result of flow field in the air-blast freezer. The velocity magnitude shows a good agreement with measured data. The flow field shows a large circumfluence with small velocity in the center of the flow field, and may lower the freezing speed of food. The velocity magnitude ranges from $0.5 \mathrm{~m} / \mathrm{s}$ to $5 \mathrm{~m} / \mathrm{s}$, which may causes local differences of freezing process when there are numbers of food products in the freezing chamber.

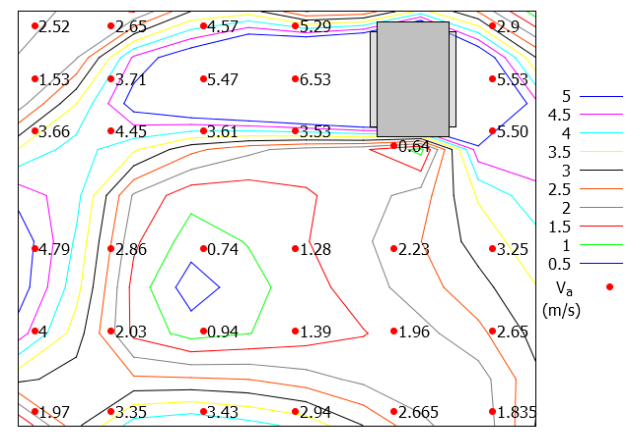

Fig. 6. Flow field predicted by CFD model.

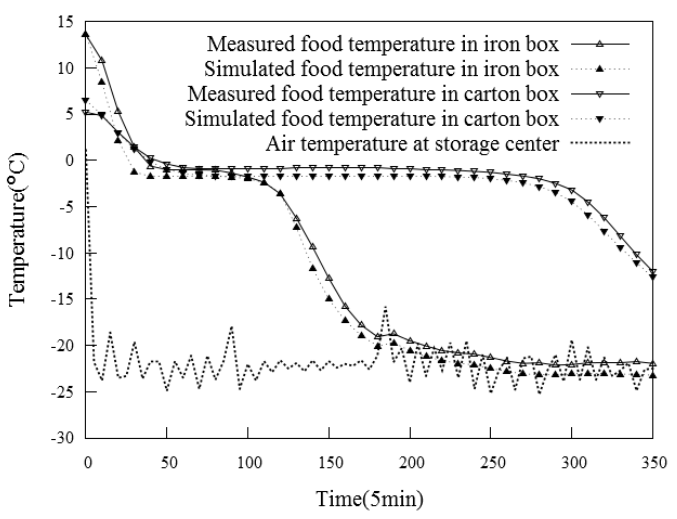

Fig. 7. Comparison of measured and simulated temperature.

The measured and simulated center temperatures of food with two types of packaging are plotted in Fig. 7, which show that both simulations fit the experimental results well. The freezing curves in Fig. 7 illustrate a typical pattern of food freezing. Because of different geometries and packaging material, it took 17 hours less to freeze the food packaged in iron box than that in carton box if $15^{\circ} \mathrm{C}$ is considered to be the freezing completion temperature. Due to the control algorithm, the air temperature shows a frequent fluctuation during freezing process. Little difference between supply and return air temperature of air cooler is observed, which indicates the space uniformity of air temperature in freeing chamber.

Fig. 8(a) shows the effect of air parameters on freezing time, while Fig. $8 \mathrm{~b}$ shows that on freezing speed. As the air velocity increases, freezing time decreases relatively. That influence becomes slighter and slighter as the air velocity increases. The same trend can be seen on the influence of air temperature, which shows a more significant impact than air velocity. For the freezing speed, the air velocity has a reverse impact, as well as the air temperature. Except that the freezing speed decreases almost linearly as the air temperature increases, which indicates that decreasing the air temperature has little impact on freezing time when the air temperature is low enough, but is still meaningful to increase the freezing speed.

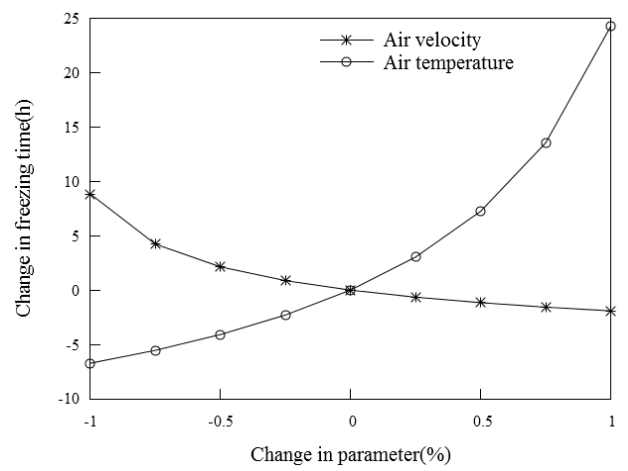

(a) Effects of air parameters on freezing time.

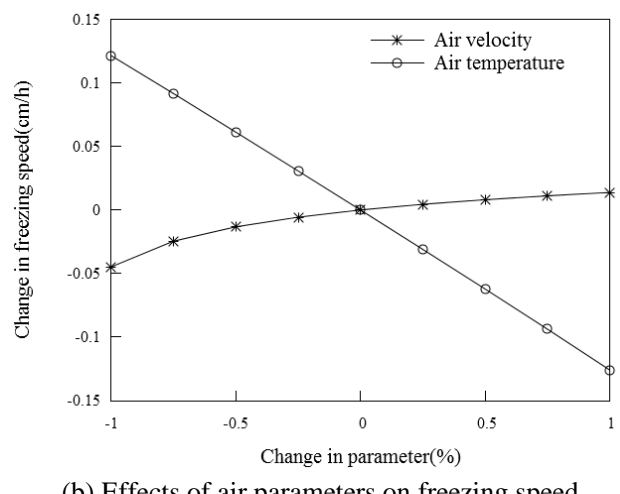

(b) Effects of air parameters on freezing speed.

Fig. 8. Effects of air parameters on food freezing.

\section{CONCLUSIONS}

A modeling on flow field in freezing chamber was achieved using CFD code, which fits well with the experimental results. The surface heat transfer coefficient was calculated and fitted into a regression equation. Finally the simulation on food freezing was conducted, which shows a significant effect of packaging material. The influences of air temperature and velocity on freezing were analyzed. Air velocity has less effect on freezing as the velocity increases. The effect of air temperature on freezing time displays a similar trend, while the freezing speed increases almost linearly with the air temperature decreasing. For lower air temperature, it is still meaningful to decrease air temperature in order to achieve higher freezing speed. 


\section{REFERENCES}

[1] F. J. Trujillo and Q. T. Pham, "A computational fluid dynamic model of the heat and moisture transfer during beef chilling," International Journal of Refrigeration, vol. 29, no. 6, pp. 998-1009, Sep. 2006.

[2] P.-S. Mirade, A. Kondjoyan, and J.-D. Daudin, "Three-dimensional CFD calculations for designing large food chillers," Computers and Electronics in Agriculture, vol. 34, no. 1-3, pp. 67-88, 2002.

[3] A. Kondjoyan, "A review on surface heat and mass transfer coefficients during air chilling and storage of food products," International Journal of Refrigeration, vol. 29, no. 6, pp. 863-875, Sep. 2006.

[4] D.-W. Sun and Z. Hu, "CFD predicting the effects of various parameters on core temperature and weight loss profiles of cooked meat during vacuum cooling," Computers and Electronics in Agriculture, vol. 34, no. 1-3, pp. 111-127, May 2002.

[5] Z. Hu and D. W. Sun, "CFD simulation of heat and moisture transfer for predicting cooling rate and weight loss of cooked ham during air-blast chilling process," Journal of Food Engineering, vol. 46, no. 3, pp. 189-197, Nov. 2000.

[6] Q. T. Pham, F. J. Trujillo, and N. McPhail, "Finite element model for beef chilling using CFD-generated heat transfer coefficients," International Journal of Refrigeration, vol. 32, no. 1, pp. 102-113, Jan. 2009.
[7] P. Verboven, B. M. Nicolaï, N. Scheerlinck, and J. de Baerdemaeker, "The local surface heat transfer coefficient in thermal food process calculations: A CFD approach," Journal of food engineering, vol. 33, no. 1, pp. 15-35, 1997.

[8] D. W. Sun, Handbook of Frozen Food Processing and Packaging. CRC Press, 2012.

[9] I. international du froid, Recommendations for the Processing and Handling of Frozen Foods., IIF = IIR, 2006.

[10] J. Xie, X. H. Qu, J. Y. Shi, and D. W. Sun, "Effects of design parameters on flow and temperature fields of a cold store by CFD simulation," Journal of Food Engineering, vol. 77, no. 2, pp. 355-363, Nov. 2006.

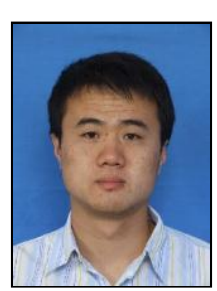

Guiqiang Wang was born in 1983 in Dalian, China. He received his B.E degree in heating, ventilating and air conditioning from Harbin Institute of Technology, China during 2003-2007, and M.E degree during 2007-2009 from the same University. He is currently pursuing his Ph.D degree in Harbin Institute of Technology, China. 